\title{
Therapeutic application of monoclonal antibodies in multiple sclerosis: focus on alemtuzumab
}

This article was published in the following Dove Press journal:

Degenerative Neurological and Neuromuscular Disease

30 September 2011

Number of times this article has been viewed

\section{Masaaki Niino \\ Department of Clinical Research, Hokkaido Medical Center, Sapporo, Japan}

Correspondence: Masaaki Niino Department of Clinical Research, Hokkaido Medical Center, I-I, Yamanote 5-jo 7-chome, Nishi-ku, Sapporo 063-0005, Japan

$\mathrm{Tel}+8|||| 6|| 8|| \mid$

Fax +8I II 6II 5820

Email niino@hok-mc.hosp.go.jp

\begin{abstract}
Recent progress in the treatment of multiple sclerosis (MS) is significant, and the potential of monoclonal antibodies (mAbs) for the treatment of MS has been highlighted. Natalizumab demonstrated a high level of efficacy for MS and is the first mAb to be approved for treatment of MS. Clinical trials of several types of mAbs for treatment of MS are in progress, and $\mathrm{mAbs}$ are expected to become the new choice of treatment for MS. Alemtuzumab is one of the most promising mAbs for treatment for MS, despite some side effects to be considered such as autoimmune hyperthyroidism, Goodpasture's syndrome, and autoimmune idiopathic thrombocytopenic purpura. Any therapeutic agents for MS may carry risks of short- or long-term side effects; however, information regarding the long-term side effects of these new agents is lacking. Long-term adverse effects can often be recognized after the approval of agents. Here, recent progress on $\mathrm{mAbs}$ for the treatment of MS is reviewed, with a focus on alemtuzumab.
\end{abstract}

Keywords: multiple sclerosis, monoclonal antibody, alemtuzumab, therapy, experimental autoimmune encephalomyelitis

\section{Introduction}

Multiple sclerosis (MS) is an inflammatory and demyelinating disease of the central nervous system. Current data strongly suggest that MS is an immune-mediated disease and inflammation is the driving force for neurodegeneration. However, the inflammatory response is much more complex compared with that seen in experimental models of autoimmune encephalomyelitis. ${ }^{1}$ Furthermore, MS is not a homogeneous disease, and the formation of MS lesions is complex, involving cytokines, chemokines, and immunoglobulins. In view of the disease heterogeneity of MS and limited access to ex vivo specimens, different approaches must be undertaken to better understand new therapeutic challenges. ${ }^{2}$

Since the early 1990s, interferon beta (IFN $\beta$ ) and glatiramer acetate have been first-line disease-modifying therapies (DMTs) to reduce the rate of clinical relapse. However, the clinical efficacy of these DMTs is suboptimal and approximately two-thirds of patients with relapsing remitting MS (RRMS) continue to experience relapses while taking these therapies for more than 2 years. ${ }^{3-6}$ Most DMTs have limited effects, and have little or no impact on the long-term progression of MS. Further agents are required, which have improved efficacy with acceptable safety, and extensive approaches are progressing in regards to treatment for MS. ${ }^{7}$ Experimental autoimmune encephalomyelitis (EAE), which is an animal model of MS, is used for developing new agents for MS treatment; however, there are some differences between EAE 
and MS. It seems naive to believe that the whole spectrum of MS can be covered by a single or even several different EAE models, and there are obvious limitations of EAE as a model of MS. ${ }^{2}$ Monoclonal antibodies (mAbs) are considered to be promising agents for treatment of many diseases, and various types of mAbs have been evaluated for treatment of EAE and MS, especially for reducing relapse rates. Natalizumab was approved as the first mAb treatment for relapsing MS in November 2004 by the United States Food and Drug Administration (FDA). However, soon after approval, progressive multifocal leukoencephalopathy (PML) was reported in patients treated with natalizumab, which led to market suspension of this mAb in February 2005. In 2006, natalizumab was relaunched in the United States, and since then, natalizumab has been used as second-line monotherapy for active relapsing MS. Clinical trials on other selected $\mathrm{mAbs}$ for MS such as rituximab and daclizumab are in progress and some will be options for treatment of MS. Another mAb, alemtuzumab (also known as Campath-1H), can be considered an option for treatment of MS based on previous clinical trials. Recent clinical trial data demonstrated that alemtuzumab had superior and sustained effects in terms of relapse rate, magnetic resonance imaging (MRI) findings, and disability, compared to subcutaneous IFN $\beta-1 \mathrm{a} .{ }^{8}$ Here, $\mathrm{mAbs}$ as new therapeutic agents for MS is reviewed, focusing on alemtuzumab which is suggested to be a promising new therapy for MS from clinical trial data.

\section{Monoclonal antibodies}

The subtype of most therapeutic mAbs is immunoglobulin (Ig) G, which is a Y-shaped protein composed of four polypeptide chains (two light and two heavy). Human IgG includes four subclasses, IgG1 to IgG4. mAbs also consist of fragment crystallizable $\left(\mathrm{F}_{\mathrm{c}}\right)$ domains and fragment antigen-binding $\left(\mathrm{F}_{\mathrm{ab}}\right)$ domains. The $\mathrm{F}_{\mathrm{c}}$ domains modulate an appropriate immune response by binding to a specific class of $\mathrm{F}_{\mathrm{c}}$ receptors and to other immune molecules such as complement proteins. The $\mathrm{F}_{\mathrm{ab}}$ regions determine how the antibody will bind to the epitope of its target molecule as well as the degree of affinity. ${ }^{9}$

mAbs block specific molecules relevant to the pathogenesis of various diseases, and the therapeutic effects of mAbs are determined by their target molecule and its function. mAbs are already licensed for the treatment of several diseases, such as cancers and autoimmune diseases. Recently, the potential of mAbs for the treatment of MS has been highlighted. Initially, murine mAbs were developed but showed a high incidence of allergic reactions in humans caused by strong anti-mouse antibody responses. ${ }^{10}$ Next, chimeric antibodies, which consist of the variable region of a murine $\mathrm{mAb}$ linked to a human constant region, were developed. Chimeric mAbs typically consist of about $33 \%$ murine and $67 \%$ human components. ${ }^{11}$ Chimeric antibodies such as rituximab (including "xi" in the name) were expected to lead to better tolerance although reactions related to infusion were still common. In addition, humanized antibodies such as natalizumab and alemtuzumab (including "zu" in the name) were found to produce fewer allergic reactions. Humanized mAbs, which are grafted into the variable region of only those residues that determine antigen specificity on a human $\mathrm{mAb}$ framework, are limited to 3\%-10\% murine and at least $90 \%$ human components. ${ }^{10,11}$ Fully human mAbs such as ofatumumab and adalimumab (including "mu" in their name) have a $100 \%$ human structure.

An mAb targets a specific cell type, and can either block or mask the target structure, and thereby inhibit a specific function or directly induce intracellular signaling, respectively. ${ }^{12}$ Currently, several mechanisms of action of mAbs are considered: antagonism of receptors and ligands, signaling by direct binding to receptors, complementdependent cytolysis (CDC) (the classical pathway $<\operatorname{IgG} 1$, $\mathrm{IgG} 2$, and $\mathrm{IgG} 3>$ or the alternative pathway $<\operatorname{IgG} 4>$ ) in which the $\mathrm{F}_{\mathrm{c}}$ receptor activates the complement system, and antibody-dependent cellular cytolysis (ADCC), in which the $\mathrm{mAb}$ binds to $\mathrm{F}_{\mathrm{c}}$ receptors on the surface of cytotoxic cells such as macrophages and natural killer (NK) cells. ${ }^{12}$ However, in spite of their high specificity for a target ligand, the in vivo effects of $\mathrm{mAb}$ cannot always be accurately predicted.

\section{mAbs as a treatment for MS}

Many types of recombinant mAbs have been developed in the past few decades and $\mathrm{mAbs}$ have been used for treatment of neoplastic disorders for more than 20 years. In MS, the $\mathrm{T}$ cell was the main target for treatment, and mAbs against T cells such as anti-CD2, anti-CD3, and anti-CD4 were found to be effective treatment for EAE. ${ }^{13-16}$ However, treatment with anti-CD3 or anti-CD4 mAbs was not effective for MS. ${ }^{17}$ In the 1990s, selective molecular approaches to MS therapy also comprised strategies to neutralize tumor necrosis factor alpha (TNF $\alpha)$; however, clinical trials of these agents were not successful. ${ }^{18}$ A number of mAbs that are currently approved or in clinical trials are considered among the most promising new therapies for MS (Table 1).

Natalizumab is a humanized monoclonal IgG4 antibody that selectively inhibits the $\alpha 4$-subunit (CD49d), which 
Table I Four therapeutic monoclonal antibodies for multiple sclerosis

\begin{tabular}{lllll}
\hline mAb & Target molecule & Antibody type & lgG subclass & Mechanisms of action \\
\hline Natalizumab & CD49d (alpha4-integrin) & Humanized & $\lg G 4$ & Antagonism of CD49d \\
Rituximab & CD20 & Chimeric & $\lg G \mid+$ murine components & CDC, ADCC, apoptosis of B cells \\
Daclizumab & CD25 & Humanized & $\lg G \mid$ & Antagonism of CD25 \\
Alemtuzumab & CD52 & Humanized & $\lg G \mid$ & CDC, ADCC, apoptosis of the target cell \\
& & & without complement or immune effector cells \\
\hline
\end{tabular}

Abbreviations: ADCC, antibody-dependent cellular cytolysis; CDC, complement-dependent cytolysis; IgG, immunoglobulin G; mAb, monoclonal antibody.

constitutes very late antigen (VLA)-4 with $\beta 1$-integrin (CD29), as well as $\alpha 4 \beta 7$ integrin. Antibody-integrin binding prevents the adhesion and migration of immune cells, such as T and B cells, and monocytes across the blood-brain barrier. Natalizumab significantly, albeit partially, diminished VLA-4 expression on circulating immune cells, ${ }^{19}$ and natalizumab is currently the only $\mathrm{mAb}$ approved to treat MS. It was shown that natalizumab treatment results in alteration of the CD4:CD8 ratio in the cerebrospinal fluid. ${ }^{20}$ In the Natalizumab Safety and Efficacy in Relapsing Remitting Multiple Sclerosis (AFFIRM) trial with 942 RRMS patients who received either $300 \mathrm{mg}$ natalizumab or placebo every 4 weeks for 2 years, the relapse rate dropped by $68 \%$, and the development of new or enlarging lesions on T2-weight and gadolinium-enhancing MRI was reduced by $83 \%$ and $92 \%$, respectively. ${ }^{21}$ Because of these results and the data from other clinical trials, natalizumab was approved at a dose of $300 \mathrm{mg}$ monthly for relapsing MS in November 2004 by the FDA. However, soon after approval, three cases of PML were reported (two with MS in the Safety and Efficacy of Natalizumab in Combination with Interferon Beta-1a in Patients with Relapsing-Remitting Multiple Sclerosis [SENTINEL] study and one with Crohn's disease) ${ }^{22-24}$ which led to the market suspension of natalizumab in February 2005, and two PML patients with MS had received combination therapy with natalizumab and intramuscular IFN $\beta$ - 1 a. Taken together, natalizumab has been restricted to use as a secondline monotherapy for active relapsing MS after natalizumab was relaunched in the United States and approved by the European Medicines Agency in 2006. However, it is currently known that PML can occur even with natalizumab monotherapy. Identification of patients at lower or higher risk for developing PML may allow more appropriate use of natalizumab, and the recent two-step assay for antibodies for John Cunningham virus in serum and plasma may provide a tool for stratification of patients into groups at higher risk for PML and those at lower risk..$^{25}$

Rituximab is a chimeric murine/human $\operatorname{IgG} 1 \kappa \mathrm{mAb}$ that targets and selectively depletes CD20, which is a differentiation antigen found on normal and malignant pre $\mathrm{B}$ and mature B lymphocytes. Rituximab has been approved for treatment of rheumatoid arthritis and B cell lymphomas. The Phase II Helping to Evaluate Rituxan ${ }^{\circledR}$ in Relapsing Remitting Multiple Sclerosis (HERMES) trial in RRMS patients demonstrated that patients who received rituximab for 48 weeks had reduced counts of total new gadoliniumenhancing lesions at weeks $12,16,20$, and $24(P<0.001)$, and these results were sustained for 48 weeks $(P<0.001)$, compared with patients who received placebo. ${ }^{26}$ The proportion of patients with relapses in the rituximab group $(n=69)$ was significantly reduced at weeks $24(P=0.02)$ and 48 $(P=0.04)$ compared with patients in the placebo group $(\mathrm{n}=35) .{ }^{26}$ In this clinical trial, over $90 \%$ of MS patients treated with rituximab experienced infusion-associated adverse events, most of which were mild to moderate in severity. ${ }^{26}$ The incidence of any infection was similar in the placebo group and the rituximab group. ${ }^{26} \mathrm{~A}$ recent Phase II/III study of rituximab in primary progressive MS (PPMS) was less promising and did not meet its primary endpoint of delaying sustained progression of disability although the results suggested that B cell depletion may be effective in younger patients with PPMS and inflammatory MRI-detected disease activity. ${ }^{27}$ In this study, serious infections occurred higher in the rituximab-treated group $(4.5 \%)$ compared to the placebo group $(<1.0 \%) .{ }^{27}$ Regarding adverse effects of rituximab in patients with systemic lupus erythematosus or malignancies, some cases of PML have been reported during treatment. ${ }^{28-31}$ Rituximab can also cause fatal infusion reactions and severe mucocutaneous reactions. ${ }^{32}$ Two newer generation anti-CD20 mAbs, ocrelizumab $^{33}$ (a humanized $\mathrm{mAb}$ ) and ofatumumab ${ }^{34}$ (a fully human $\mathrm{mAb}$ ) are currently in clinical trials, aiming to further develop the promising therapeutic concept of B cell depletion in MS patients.

Daclizumab is a humanized $\operatorname{IgG1} \mathrm{mAb}$ raised against CD25 [ $\alpha$-chain of the interleukin (IL)-2 high-affinity receptor], which is specifically expressed on activated $\mathrm{T}$ and $\mathrm{B}$ cells, NK cells, monocytes as well as regulatory T and NK cells. IL-2 induces secretion of proinflammatory cytokines and is able to sustain the growth of T, B, and NK cells. ${ }^{35}$ 
Daclizumab reduces the proliferation and activation of these cells by blocking IL-2 signaling via its high-affinity receptor, and increases the number of CD56 $6^{\text {bright }} \mathrm{NK}$ cells, which help to regulate the immune cells. ${ }^{36}$ Daclizumab was approved for the prevention of allotransplant rejection and adult $\mathrm{T}$ cell leukemia. In three small open-label studies in MS, in two of which patients with RRMS with incomplete clinical and MRI responses to IFN $\beta$ received add-on therapy with daclizumab, daclizumab reduced MRI activity significantly and improved clinical outcome measures. ${ }^{37-39}$ The question of synergy between IFN $\beta$ and daclizumab was addressed; daclizumab monotherapy was effective in most patients who experienced persistent MS disease activity with IFN $\beta$ therapy. ${ }^{40}$ IFN $\beta$-daclizumab combination therapy or higher dosages of daclizumab may be necessary to achieve optimal therapeutic response in all patients. ${ }^{40} \mathrm{~A}$ Phase II trial demonstrated that daclizumab 1 or $2 \mathrm{mg} / \mathrm{kg}$ administered subcutaneously every 2 weeks in combination with IFN $\beta$ therapy for 24 weeks resulted in $72 \%$ reduction in the number of new or enlarged MS lesions when compared with IFN $\beta$ therapy alone in patients with active MS. ${ }^{41}$ The new Phase III trial (Daclizumab HYP Efficacy Compared to Interferon Beta 1-a Study for Multiple Sclerosis [DECIDE]), comparing a subcutaneous injection of daclizumab $150 \mathrm{mg}$ once every 4 weeks with weekly injections of IFN $\beta 1$ a, is ongoing. ${ }^{42}$ Daclizumab treatment was generally tolerated we $11^{42}$ and has not been reported to be associated with PML.

Ustekinumab is a subcutaneously or intravenously administered fully human monoclonal IgG1 $\kappa$ antibody directed against the common $\mathrm{p} 40$ subunit of IL-12 and IL-23, which appear to play a key role in the pathogenesis of MS. Ustekinumab has demonstrated efficacy in the treatment of plaque psoriasis. ${ }^{43}$ Neutralizing these cytokines via an $\mathrm{mAb}$ resulted in significant suppression of the development and the severity of EAE..$^{44}$ In a randomized, double-blind, placebo-controlled, multi center Phase II study, 249 RRMS patients were assigned randomly to one of five groups receiving placebo or four different doses of ustekinumab, and observed for change in the number of new gadolinium-enhancing T1 lesions at week 23 . There was no significant change in the cumulative number of new gadolinium-enhancing lesions for any dosage groups vs placebo while ustekinumab was generally well tolerated. ${ }^{45}$

As mentioned above, cases of PML associated with treatment with some mAbs have been reported. PML, caused by the John Cunningham virus, is a severe, progressive, rare, and usually fatal opportunistic demyelinating disease of the brain, and generally occurs in immunocompromised patients. There are several possible mechanisms of induction of PML by mAbs, such as loss of immune surveillance by a reduction of immune cells in the perivascular spaces and cerebrospinal fluid, suppression of the cellular immune system, and upregulation of transcription factor genes that might increase viral synthesis; ${ }^{46}$ however, the exact mechanism remains unclear. There are currently no approved or proven therapies for PML; however, there are several possible treatment interventions such as antiviral agents, immunomodulatory therapies, hematopoietic growth factors, plasma exchange, intravenous immunoglobulins, leukapheresis, and autotransfusion of leukocytes.

\section{Alemtuzumab}

A recent study demonstrated that alemtuzumab has clinical superiority to a current standard first line therapy, subcutaneous IFN $\beta-1 \mathrm{a},{ }^{8}$ which suggests that alemtuzumab is a promising new therapy for MS. Alemtuzumab (or Campath-1H) is a recombinant humanized $\operatorname{IgG} 1 \kappa \mathrm{mAb}$ directed against the CD52 antigen. The name Campath derives from Cambridge Pathology. ${ }^{47}$ The CD52 antigen, which is a glycosylated protein linked to the cell membrane by a glycosylphosphatidylinositol anchor, is not internalized or modulated upon crosslinking and is a consistent target. This antigen is highly expressed on the cell surface of normal lymphocytes, monocytes, and macrophages as well as on chronic lymphocytic leukemia cells. Normal hematopoietic stem cells, erythrocytes, and platelets lack CD52 surface expression; however, neutrophils express low levels of CD52. ${ }^{48}$ The physiologic role of CD52 is unknown, but ligation and crosslinking of T cell CD52 by alemtuzumab demonstrates that the molecule can induce signal transduction via $\mathrm{T}$ cell receptors. ${ }^{49}$ It has also been suggested that CD52 may have a role in the activation of regulatory T cells.$^{50} \mathrm{It}$ is considered that binding of alemtuzumab to CD52 on lymphocytes induces CDC and ADCC (Figure 1). ${ }^{51}$ The results of a recent study with a transgenic mouse expressing human CD52 suggested that lymphocyte depletion and cytokine induction by alemtuzumab were primarily independent of complement, which means that ADCC but not CDC is important. ${ }^{52}$ It has also been suggested that alemtuzumab may enhance lymphocyte apoptosis without complement or immune effector cells (Figure 1)..$^{53}$

The early Campath antibodies were created from rat hybridomas. Initially, IgM antibodies were more efficient in lysing lymphocytes with human complement than the $\mathrm{IgG}$ forms and one of these rat IgM reagents, Campath-1M, was 

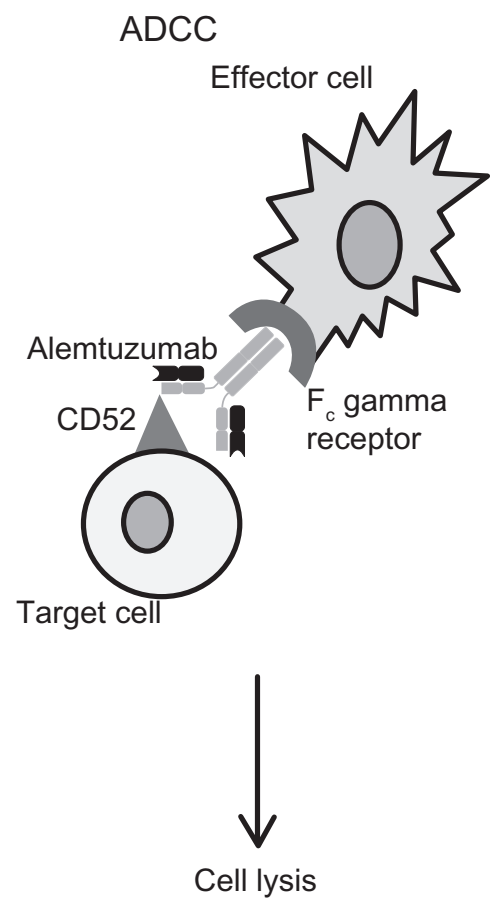
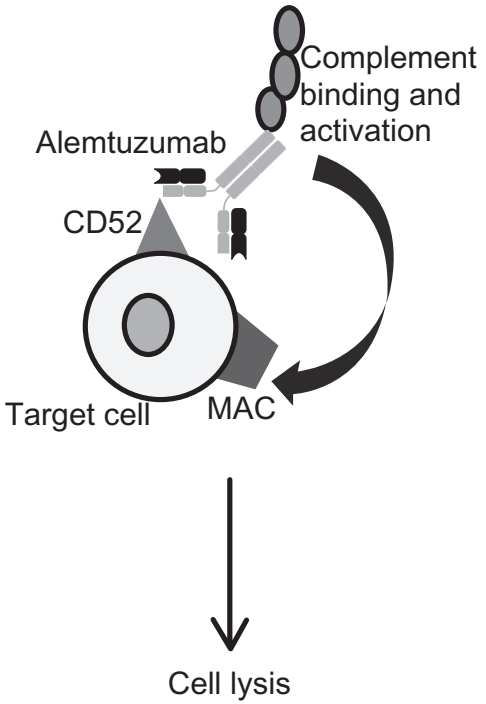

Direct apoptosis
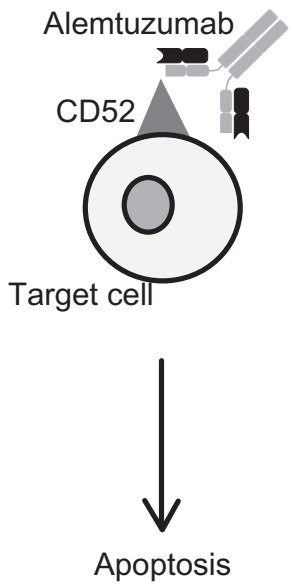

Figure I Schematic representation of the putative mechanisms mediating the activity of alemtuzumab. In antibody-dependent cellular cytolysis (ADCC), $\mathrm{F}_{c}$ gamma receptors on the surface of immune effector cells, such as natural killer cells, macrophages, monocytes, and eosinophils, bind the $F_{c}$ region of alemtuzumab which is bound to a target cell, causing the destruction of the target cell. In complement-dependent cytolysis (CDC), the $\mathrm{Cl} q$ binds the antibody and this binding triggers the complement cascade which leads to the formation of the membrane attack complex (MAC) at the surface of the target cell, as a result of the classical pathway of complement activation. Alemtuzumab may also enhance apoptosis of the target cell without complement or immune effector cells.

used for the first clinical pilot study. ${ }^{47}$ Then, from basic studies, it was found that the rat IgG2b isotype was by far the most effective isotype in harnessing the cell-mediated lytic mechanisms, and a rat IgG2b antibody, Campath-1G, was manufactured.$^{47}$ Although Campath-1G was clearly active in humans, antiglobulin responses to rodent antibodies were suggested to be a key problem in the use of Campath-1G, and therefore humanized IgG1 mAb (Campath-1H; alemtuzumab) was manufactured to clinical grade for therapeutic use. ${ }^{47}$ Initially, alemtuzumab was generated for the treatment of non-Hodgkin's lymphoma, ${ }^{54}$ and also used in the treatment of rheumatoid arthritis ${ }^{55}$ and vasculitis. ${ }^{56}$ Alemtuzumab received accelerated approval in the United States and Europe in 2001 for patients with chronic lymphocytic leukemia who had been treated with alkylating agents and in whom fludarabine therapy had failed. Then, alemtuzumab received full approval and an expanded indication in September 2007 in the United States and in January 2008 in Europe. ${ }^{51}$

A preliminary study involving seven patients with MS showed that a single pulse of alemtuzumab suppressed MRI-assessed disease activity for at least 6 months. ${ }^{57}$ In a small clinical trial with 14 secondary progressive MS (SPMS) or PPMS patients, the doses of and durations of treatment with alemtuzumab, and combination therapies with alemtuzumab (eg, methylprednisolone and antiCD4 mAbs) were different among patients. ${ }^{58}$ The study results showed that twelve patients experienced transient worsening of existing symptoms, or recurrence of previous clinical manifestations, coinciding with the first infusion of alemtuzumab, which correlated with increased levels of circulating cytokines.$^{58}$ By contrast, two patients who were immediately pretreated with methylprednisolone had no clinical or laboratory effects. ${ }^{58}$

In an open-label clinical trial, relapses and radiologic markers (contrast-enhancing MRI lesions) of cerebral inflammation were effectively suppressed for 18 months after a single pulse of alemtuzumab in SPMS patients. However, about half the patients continued to experience progressive disability with increasing brain atrophy on MRI. On the other hand, in the relapsing group, nine of 15 patients observed 1 year later showed a sustained improvement in the Expanded Disability Status Scale (EDSS), giving a mean change in disability of -1.2 EDSS points at 2 years when compared with baseline. ${ }^{57,59-61}$ These results and the difference of effects on disability between patients with SPMS and RRMS may suggest that in chronic MS, ongoing disease progression 
is not caused by active inflammation but mediated by an independent neurodegenerative process. ${ }^{60}$ Furthermore, when administered to patients with early-stage MS with little accumulated disability but a high level of clinical activity, alemtuzumab therapy stabilized disease progression. ${ }^{60}$ From the data of clinical trials, alemtuzumab appears to be active in the early, more inflammatory stage of MS.

A Phase II, randomized, controlled, rater-blinded clinical trial was designed to compare the safety and efficacy of two doses (12 and $24 \mathrm{mg}$ per day) of alemtuzumab with subcutaneous IFN $\beta-1 \mathrm{a}$ (44 $\mu \mathrm{g}$ three times per week) in 334 patients with early RRMS who had EDSS scores of three or less and onset of symptoms within the previous 36 months at the time of screening. Patients treated with alemtuzumab were given intravenous infusions on five consecutive days during the first month and on three consecutive days at months 12 and 24. The results of the study demonstrated a significant reduction by alemtuzumab of the annualized relapse rates (by $74 \%$ compared with IFN $\beta-1 a$ ). ${ }^{8}$ Further analysis revealed that the rate of free clinical disease activity defined as no relapses and no sustained accumulation of disability at 36 months was significantly better in the alemtuzumab-treated group (Kaplan-Meier estimate 71.8\%) compared to the IFN $\beta$-1a-treated group (Kaplan-Meier estimate $42.6 \%) .^{62}$ Lesion burden, and brain volumes on MRI were also positively affected at 36 months. ${ }^{8}$ Moreover, EDSS disability scores were improved in the group treated with alemtuzumab by 0.39 points, whereas scores worsened in the group treated with IFN $\beta$ - 1 a by 0.38 points. ${ }^{8} \mathrm{~A}$ further study demonstrated that immune cells regenerating after alemtuzumab treatment produce significantly greater brainderived neurotrophic factor, ciliary neurotrophic factor, platelet-derived growth factor, and fibroblast growth factor, and that secretion of brain-derived neurotrophic factor, ciliary neurotrophic factor, and platelet-derived growth factor occurs specifically in response to the myelin antigen, myelin basic protein. ${ }^{63}$ The increased lymphocytic secretion of neurotrophins after treatment with alemtuzumab may be capable of promoting neuronal survival, axon growth, and the survival and maturation of oligodendrocytes following the sustained improvement in disability with early active RRMS treated with alemtuzuamb. ${ }^{63}$

Treatment with alemtuzumab produces a rapid and profound lymphopenia, followed by lymphocyte regeneration. However, the recovery speed varies among cell types and the lymphocyte repertoire is modulated. In fact, monocytes recover quickly with the pretreatment level reached within 3 months, whereas $\mathrm{CD}^{+}$lymphocyte depletion is prolonged. $\mathrm{CD} 4^{+}$
$\mathrm{T}$ cells are particularly slow to recover and total $\mathrm{CD} 4^{+} \mathrm{T}$ cell numbers were reported to remain below $50 \%$ of pretreatment levels at 12 months. ${ }^{60,64}$ Alemtuzumab infusion altered the immune repertoire with increased $\mathrm{CD} 4{ }^{+} \mathrm{CD} 25^{\text {hi }} \mathrm{FoxP} 3^{+}$regulatory $\mathrm{T}$ cells and increased CD45RO ${ }^{+}$memory T cells. ${ }^{64}$

The level of B cells rapidly returns to baseline by 3 months after exposure to alemtuzumab, and to higher levels by 12 months..$^{60,64,65}$ One month after treatment, the most abundant B cell subtype is immature transitional 1B cells $\left(\mathrm{CD} 19^{+} / \mathrm{CD} 27^{-} / \mathrm{CD} 23^{-}\right)$and alemtuzumab induces prolonged depletion of memory B cells. ${ }^{65}$ At the same time, there is an increase in serum levels of B cell activating factor, which is sustained for at least 12 months. ${ }^{65}$ Memory and naive human B cells express distinct profiles of effector cytokines, thus IL-10 is produced almost exclusively by naive B cells whereas the proinflammatory cytokines lymphotoxin and TNF $\alpha$ are largely produced by memory B cells. ${ }^{66}$ Reconstitution of B cell subsets following the change in profile of the effector cytokines may be associated with the effects of alemtuzumab in MS.

$\mathrm{mAb}$ therapy may induce antiglobulin responses following impairment of efficacy. In a clinical trial of alemtuzumab vs INF $\beta-1 \mathrm{a}$ in early MS, one of $208(0.5 \%)$ and 51 of 194 patients $(26.3 \%)$ had significant alemtuzumab-binding antibodies at months 12 and 24, respectively (assay detection threshold: $2000 \mathrm{U} / \mathrm{mL}) .{ }^{8}$ Although the antibodies had no effect on the efficacy of alemtuzumab in this clinical trial, another study examined whether high doses of a monomeric, nonbinding $\mathrm{mAb}, \mathrm{SM} 3$, which reduces its binding capacity to CD52, could minimize immunogenicity to subsequent exposure of alemtuzumab. ${ }^{67}$ In this latter study, the lower assay detection threshold $(444 \mathrm{U} / \mathrm{mL})$ was used, and at follow-up after 13 months, 1 month after the second alemtuzumab infusion, four of 19 (21\%) patients had detectable serum antialemtuzumab antibodies compared with 145 of 197 (74\%) patients who received two cycles of alemtuzumab without SM3 in the Phase II CAMMS223 trial $(P<0.001) .{ }^{67}$ The efficacy and safety profile of alemtuzumab was unaffected by SM3 pretreatment although more infections were observed in the SM3 pretreatment group. ${ }^{67}$ These data suggested that monomeric, nonbinding $\mathrm{mAbs}$ may reduce the immunogenicity of biologic agents although larger studies are necessary to confirm the efficacy and safety of this approach.

The first and earliest adverse effect of alemtuzumab infusion was an acute cytokine-release syndrome consisting of pyrexia, headache, malaise, and urticarial rash. This is typically accompanied by a transient exacerbation of neurologic symptoms..$^{57,68}$ These symptoms associated with 
cytokine-release syndrome are substantially ameliorated by pretreatment with steroids. ${ }^{59}$ In a comparison between intravenous and subcutaneous administration of alemtuzumab, intravenous administration has been correlated with a higher rate of first-dose side effects (eg, flu-like symptoms, chills, rigor, hypotension, nausea, vomiting, rash, urticaria, and bronchospasm) compared to subcutaneous application. ${ }^{48}$

There are three important safety concerns regarding treatment with alemtuzumab with respect to infection, malignancy, and autoimmune disease ${ }^{69}$ With respect to infection, herpes viruses have been reported in between $1.8 \%$ and $18.0 \%$ of patients undergoing transplant premedication with alemtuzumab. ${ }^{70}$ However, in MS patients treated with alemtuzumab to date, the incidence of any serious opportunistic infections has been low. ${ }^{8}$ On the other hand, some serious autoimmune diseases associated with treatment with alemtuzumab have been reported, including autoimmune hyperthyroidism (Grave's disease), renal failure due to Goodpasture's syndrome, and autoimmune idiopathic thrombocytopenic purpura ${ }^{68}$ One patient with idiopathic thrombocytopenic purpura died following treatment with alemtuzumab, and after the report of two further cases, the data and safety monitoring board suspended the administration of alemtuzumab between September 2005 and May 2007. ${ }^{8}$ Furthermore, an additional $5.5 \%$ of patients developed sustained nonthyroid autoantibodies without clinical disease. ${ }^{60}$ In view of the occurrence of these autoimmune diseases, it is conceivable that alemtuzumab-mediated lymphocyte depletion may result in disturbed regulatory function. ${ }^{71}$ Recently, it was demonstrated that autoimmunity arises in patients who developed lymphopenia-associated autoimmunity after alemtuzumab treatment of MS and who had greater levels of T cell apoptosis and $\mathrm{T}$ cell cycling driven by genetically determined higher levels (twofold) of IL-21 than patients who did not develop autoimmunity. ${ }^{72}$ These data suggested that, by driving cycles of T cell expansion and death to excess, IL-21 increases the probability of generating self-reactive $\mathrm{T}$ cells and, hence, autoimmunity. ${ }^{72}$

No cases of PML have been reported among MS patients treated with alemtuzumab; however, a lung transplant recipient who received treatment for episodes of acute rejection with steroids, antithymocyte globulin, and alemtuzumab, in addition to maintenance immunosuppression was diagnosed with PML. ${ }^{73}$

There are two multinational, randomized, rater-blinded, Phase III studies, the Comparison of Alemtuzumab and Rebif $^{\circledR}$ Efficacy in Multiple Sclerosis (CARE-MS) I and II. CARE-MS I enrolled patients who have not previously received treatment to suppress MS, except steroids, and CARE-MS II enrolled patients who previously received an adequate trial of DMTs but continued to relapse while being treated. CARE-MS I and II were designed to investigate the efficacy and safety of two different doses of alemtuzumab as treatment for RRMS, in comparison with subcutaneous IFN $\beta-1 a .{ }^{74,75}$ CARE-MS I has been completed and CARE-MS II is currently closed to new enrollment. The data from these studies will provide more information on the efficacy and safety of alemtuzumab in the near future.

\section{Conclusion}

First-line DMTs such as IFN $\beta$ and glatiramer acetate have long been used to treat MS and have well-established safety and tolerability profiles. However, these first-line DMTs can only reduce the frequency of new relapses by $30 \%-40 \%$ and there is a group of patients with high disease activity despite treatment with IFN $\beta$ or glatiramer acetate. Furthermore, their effects on disease progression have remained controversial. Natalizumab, the first approved $\mathrm{mAb}$ for treatment of MS, is a critical choice for patients who suffer from relapses even though they have used adequate first-line DMTs. Recently, fingolimod was approved for treatment of RRMS by the FDA and the European Medicines Agency's Committee for Medicinal Products for Human Use, with the latter recommending that fingolimod is used as a single DMT in "highly active" RRMS patients. In the near future, new agents for MS will be developed that may have more significant potential for effective treatment. Almost 20 years have passed since IFN $\beta$ and glatiramer acetate were first used for RRMS and most side effects are well known. On the other hand, the long-term safety of most new agents is not yet well defined; therefore attention should be paid when new agents are used.

Current therapies for MS have focused on reducing relapsing rates and new MS lesions. There is still a shortage of agents that inhibit progress of the disease and, furthermore, there have been no treatments to improve disability. mAbs have significant potential in the field of MS. Alemtuzumab appears to have remarkable effects to decrease the rate of relapse and possibly to reduce disease severity, especially, in patients with early RRMS. Furthermore, in chronic lymphocytic leukemia, some small clinical trials of the combination of alemtuzumab plus rituximab have been tried, ${ }^{76}$ and the combination therapy of mAbs may be one option for treatment of MS.

It was previously considered that because mAbs interfere with specific mechanisms, the maximum effectiveness may be gained with minimal adverse effects. However, this is not 
the case. Natalizumab is recommended for use in patients whose clinical benefit clearly outweighs the risks, and severe side effects may also make alemtuzumab suitable for second-line therapy for MS. The risk:benefit ratios of new DMTs should be taken into account. Further safety data regarding opportunistic infections and malignancies as well as idiopathic thrombocytopenic purpura and autoimmune thyroid disease with large populations and other ethnicities is needed to determine whether alemtuzumab can be used as therapy for MS. Furthermore, from a socioeconomic viewpoint, alemtuzumab will probably be marked as an expensive option for treatment of MS and only in selected cases, based on proper documentation of failure of other less expensive immunomodulatory agents. ${ }^{77}$ Even though $\mathrm{mAb}$ treatment for MS offers insight into the challenges of developing neurotherapeutics in MS, we still need to understand more about MS disease pathophysiology and function of $\mathrm{mAbs}$ in MS.

\section{Acknowledgment}

This work was supported in part by the Health and Labor Sciences Research Grant on Intractable Diseases (Neuroimmunological Diseases) from the Ministry of Health, Labor, and Welfare of Japan.

\section{Disclosures}

Dr Niino has received honoraria for lecturing and/or travel expenses for attending meetings from Bayer Schering Pharma, Biogen Idec, Merck Serono, Asahi Kasei Kuraray Medical Co, and Novartis.

\section{References}

1. Lassmann H. What drives disease in multiple sclerosis: inflammation or neurodegeneration? Clin Exp Neuroimmunol. 2010;1(1):2-11.

2. Gold R, Linington $C$, Lassmann $H$. Understanding pathogenesis and therapy of multiple sclerosis via animal models: 70 years of merits and culprits in experimental autoimmune encephalomyelitis research. Brain. 2006;129(Pt 8):1953-1971.

3. Interferon beta- $1 \mathrm{~b}$ is effective in relapsing-remitting multiple sclerosis. I. Clinical results of a multicenter, randomized, double-blind, placebocontrolled trial. The IFNB Multiple Sclerosis Study Group. Neurology. 1993;43(4):655-661.

4. Johnson KP, Brooks BR, Cohen JA, et al. Copolymer 1 reduces relapse rate and improves disability in relapsing-remitting multiple sclerosis: results of a phase III multicenter, double-blind placebo-controlled trial. Neurology. 1995;45(7):1268-1276.

5. Jacobs LD, Cookfair DL, Rudick RA, et al. Intramuscular interferon beta-1a for disease progression in relapsing multiple sclerosis. The Multiple Sclerosis Collaborative Research Group (MSCRG). Ann Neurol. 1996;39(3):285-294.

6. Randomised double-blind placebo-controlled study of interferon $\beta-1 \mathrm{a}$ in relapsing/remitting multiple sclerosis. Prevention of Relapses and Disability by Interferon $\beta$-1a Subcutaneously in Multiple Sclerosis (PRISMS) Study Group. Lancet. 1998;352(9139):1498-1504.
7. Niino M, Sasaki H. Update on the treatment options for multiple sclerosis. Expert Rev Clin Immunol. 2010;6(1):77-88.

8. CAMMS223 Trial Investigators; Coles AJ, Compston DA, et al. Alemtuzumab vs interferon beta-1a in early multiple sclerosis. $N$ Engl J Med. 2008;359(17):1786-1801.

9. Bielekova B, Becker BL. Monoclonal antibodies in MS: mechanisms of action. Neurology. 2010;74 Suppl 1:S31-S40.

10. Rommer PS, Stüve O, Goertsches R, Mix E, Zettl UK. Monoclonal antibodies in the therapy of multiple sclerosis: an overview. J Neurol. 2008;255 Suppl 6:28-35.

11. Kim SE. Daclizumab treatment for multiple sclerosis. Pharmacotherapy. 2009;29(2):227-235.

12. Lutterotti A, Martin R. Getting specific: monoclonal antibodies in multiple sclerosis. Lancet Neurol. 2008;7(6):538-547.

13. Sedgwick JD, Mason DW. The mechanism of inhibition of experimental allergic encephalomyelitis in the rat by monoclonal antibody against CD4. J Neuroimmunol. 1986;13(2):217-232.

14. Jung S, Toyka K, Hartung HP. Suppression of experimental autoimmune encephalomyelitis in Lewis rats by antibodies against CD2. Eur J Immunol. 1995;25(5):1391-1398.

15. Tran GT, Carter N, He XY, et al. Reversal of experimental allergic encephalomyelitis with non-mitogenic, non-depleting anti-CD3 mAb therapy with a preferential effect on $\mathrm{T}_{\mathrm{h}} 1$ cells that is augmented by IL-4. Int Immunol. 2001;13(9):1109-1120.

16. Ochi $\mathrm{H}$, Abraham $\mathrm{M}$, Ishikawa $\mathrm{H}$, et al. Oral CD3-specific antibody suppresses autoimmune encephalomyelitis by inducing $\mathrm{CD} 4^{+} \mathrm{CD} 25^{-}$ LAP+ T cells. Nat Med. 2006;12(6):627-635.

17. Weinshenker BG, Bass B, Karlik S, Ebers GC, Rice GP. An open trial of OKT3 in patients with multiple sclerosis. Neurology. 1991;41(7): 1047-1052.

18. van Oosten BW, Barkhof F, Truyen L, et al. Increased MRI activity and immune activation in two multiple sclerosis patients treated with the monoclonal anti-tumor necrosis factor antibody cA2. Neurology. 1996;47(6):1531-1534.

19. Niino M, Bodner C, Simard ML, et al. Natalizumab effects on immune cell responses in multiple sclerosis. Ann Neurol. 2006;59(5):748-754.

20. Stüve O, Marra CM, Bar-Or A, et al. Altered $\mathrm{CD}^{+} / \mathrm{CD}^{+}$T-cell ratios in cerebrospinal fluid of natalizumab-treated patients with multiple sclerosis. Arch Neurol. 2006;63(10):1383-1387.

21. Polman CH, O’Connor PW, Havrdova E, et al. A randomized, placebocontrolled trial of natalizumab for relapsing multiple sclerosis. $N$ Engl J Med. 2006;354(9):899-910.

22. Kleinschmidt-DeMasters BK, Tyler KL. Progressive multifocal leukoencephalopathy complicating treatment with natalizumab and interferon beta-1a for multiple sclerosis. N Engl J Med. 2005;353(4): 369-374.

23. Langer-Gould A, Atlas SW, Green AJ, Bollen AW, Pelletier D. Progressive multifocal leukoencephalopathy in a patient treated with natalizumab. N Engl J Med. 2005;353(4):375-381.

24. Van Assche G, Van Ranst M, Sciot R, et al. Progressive multifocal leukoencephalopathy after natalizumab therapy for Crohn's disease. N Engl J Med. 2005;353(4):362-368.

25. Gorelik L, Lerner M, Bixler S, et al. Anti-JC virus antibodies: implications for PML risk stratification. Ann Neurol. 2010;68(3):295-303.

26. Hauser SL, Waubant E, Arnold DL, et al. B-cell depletion with rituximab in relapsing-remitting multiple sclerosis. $N$ Engl $\mathrm{J} \mathrm{Med.}$ 2008;358(7):676-688.

27. Hawker K, O'Connor P, Freedman MS, et al. Rituximab in patients with primary progressive multiple sclerosis: results of a randomized double-blind placebo-controlled multicenter trial. Ann Neurol. 2009;66(4):460-471.

28. Molloy ES, Calabrese LH. Progressive multifocal leukoencephalopathy in patients with rheumatic diseases: are patients with systemic lupus erythematosus at particular risk? Autoimmun Rev. 2008;8(2): 144-146.

29. Freim Wahl SG, Folvik MR, Torp SH. Progressive multifocal leukoencephalopathy in a lymphoma patient with complete remission after treatment with cytostatics and rituximab: case report and review of the literature. Clin Neuropathol. 2007;26(2):68-73. 
30. Pelosini M, Focosi D, Rita F, et al. Progressive multifocal leukoencephalopathy: report of three cases in HIV-negative hematological patients and review of literature. Ann Hematol. 2008;87(5):405-412.

31. Tan CS, Koralnik IJ. Progressive multifocal leukoencephalopathy and other disorders caused by JC virus: clinical features and pathogenesis. Lancet Neurol. 2010;9(4):425-437.

32. Lowndes S, Darby A, Mead G, Lister A. Stevens-Johnson syndrome after treatment with rituximab. Ann Oncol. 2002;13(12):1948-1950.

33. Genentech. Study of the Efficacy and Safety of Ocrelizumab in Patients With Relapsing-Remitting Multiple Sclerosis. In: ClinicalTrials.gov [Internet]. Bethesda, MD: National Library of Medicine (US). 2008. Available at: http://clinicaltrials.gov/ct2/show/NCT00676715. Accessed on September 26, 2011. NLM identifier: NCT00676715.

34. Genmab. Ofatumumab Dose-finding in RRMS Patients. In: ClinicalTrials.gov [Internet]. Bethesda, MD: National Library of Medicine (US). 2008. Available at: http://clinicaltrials.gov/ct2/show/NCT00640328. Accessed on September 26, 2011. NLM identifier: NCT00640328.

35. Granucci F, Zanoni I, Feau S, Ricciardi-Castagnoli P. Dendritic cell regulation of immune responses: a new role for interleukin 2 at the intersection of innate and adaptive immunity. EMBO J. 2003;22(11):2546-2551.

36. Bielekova B, Catalfamo M, Reichert-Scrivner S, et al. Regulatory CD56 $6^{\text {bright }}$ natural killer cells mediate immunomodulatory effects of IL-2R $\alpha$-targeted therapy (daclizumab) in multiple sclerosis. Proc Natl Acad Sci U SA. 2006;103(15):5941-5946.

37. Bielekova B, Richert N, Howard T, et al. Humanized anti-CD25 (daclizumab) inhibits disease activity in multiple sclerosis patients failing to respond to interferon beta. Proc Natl Acad Sci U S A. 2004; 101(23):8705-8708.

38. Rose JW, Watt HE, White AT, Carlson NG. Treatment of multiple sclerosis with an anti-interleukin-2 receptor monoclonal antibody. Ann Neurol. 2004;56(6):864-867.

39. Rose JW, Burns JB, Bjorklund J, Klein J, Watt HE, Carlson NG. Daclizumab phase II trial in relapsing and remitting multiple sclerosis: MRI and clinical results. Neurology. 2007;69(8):785-789.

40. Bielekova B, Howard T, Packer AN, et al. Effect of anti-CD25 antibody daclizumab in the inhibition of inflammation and stabilization of disease progression in multiple sclerosis. Arch Neurol. 2009;66(4):483-489.

41. Wynn D, Kaufman M, Montalban X, et al. Daclizumab in active relapsing multiple sclerosis (CHOICE study): a phase 2, randomised, double-blind, placebo-controlled, add-on trial with interferon beta. Lancet Neurol. 2010;9(4):381-390.

42. Biogen Iden. Efficacy and Safety of Daclizumab High Yield Process Versus Interferon $\beta$ 1a in Patients With Relapsing-Remitting Multiple Sclerosis. In: ClinicalTrials.gov [Internet]. Bethesda, MD: National Library of Medicine (US). 2010. Available at: http://clinicaltrials.gov/ ct2/show/NCT01064401. Accessed on September 26, 2011. NLM identifier: NCT01064401.

43. Koutruba N, Emer J, Lebwohl M. Review of ustekinumab, an interleukin-12 and interleukin-23 inhibitor used for the treatment of plaque psoriasis. Ther Clin Risk Manag. 2010;6:123-141.

44. Ichikawa M, Koh CS, Inoue A, et al. Anti-IL-12 antibody prevents the development and progression of multiple sclerosis-like relapsing remitting demyelinating disease in NOD mice induced with myelin oligodendrocyte glycoprotein peptide. J Neuroimmunol. 2000;102(1):56-66.

45. Segal BM, Constantinescu CS, Raychaudhuri A, et al. Repeated subcutaneous injections of IL12/23 p40 neutralising antibody, ustekinumab, in patients with relapsing-remitting multiple sclerosis: a phase II, double-blind, placebo-controlled, randomised, dose-ranging study. Lancet Neurol. 2008;7(9):796-804.

46. Fontoura P. Monoclonal antibody therapy in multiple sclerosis: paradigm shifts and emerging challenges. MAbs. 2010;2(6):670-681.

47. Waldmann H, Hale G. CAMPATH: from concept to clinic. Philos Trans R Soc Lond B Biol Sci. 2005;360(1461):1707-1711.

48. Schweighofer CD, Wendtner CM. First-line treatment of chronic lymphocytic leukemia: role of alemtuzumab. Onco Targets Ther. 2010;3:53-67.
49. Hederer RA, Guntermann C, Miller N, et al. The CD45 tyrosine phosphatase regulates Campath-1H (CD52)-induced TCR-dependent signal transduction in human T cells. Int Immunol. 2000;12(4):505-516.

50. Watanabe T, Masuyama J, Sohma Y, et al. CD52 is a novel costimulatory molecule for induction of $\mathrm{CD}^{+}{ }^{+}$regulatory $\mathrm{T}$ cells. Clin Immunol. 2006;120(3):247-259.

51. Österborg A, Foà R, Bezares RF, et al. Management guidelines for the use of alemtuzumab in chronic lymphocytic leukemia. Leukemia. 2009;23(11):1980-1988.

52. Hu Y, Turner MJ, Shields J, et al. Investigation of the mechanism of action of alemtuzumab in a human CD52 transgenic mouse model. Immunology. 2009;128(2):260-270.

53. Nückel H, Frey UH, Röth A, Dührsen U, Siffert W. Alemtuzumab induces enhanced apoptosis in vitro in B-cells from patients with chronic lymphocytic leukemia by antibody-dependent cellular cytotoxicity. Eur J Pharmacol. 2005;514(2-3):217-224.

54. Hale G, Dyer MJ, Clark MR, et al. Remission induction in non-Hodgkin lymphoma with reshaped human monoclonal antibody CAMPATH-1H. Lancet. 1988;2(8625):1394-1399.

55. Isaacs JD, Watts RA, Hazleman BL, et al. Humanised monoclonal antibody therapy for rheumatoid arthritis. Lancet. 1992;340(8822):748-752.

56. Lockwood CM, Thiru S, Isaacs JD, Hale G, Waldmann H. Long-term remission of intractable systemic vasculitis with monoclonal antibody therapy. Lancet. 1993;341(8861):1620-1622.

57. Moreau T, Thorpe J, Miller D, et al. Preliminary evidence from magnetic resonance imaging for reduction in disease activity after lymphocyte depletion in multiple sclerosis. Lancet. 1994;344(8918):298-301.

58. Moreau T, Coles A, Wing M, et al. Transient increase in symptoms associated with cytokine release in patients with multiple sclerosis. Brain. 1996;119(Pt 1):225-237.

59. Coles AJ, Wing MG, Molyneux P, et al. Monoclonal antibody treatment exposes three mechanisms underlying the clinical course of multiple sclerosis. Ann Neurol. 1999;46(3):296-304.

60. Coles AJ, Cox A, Le Page E, et al. The window of therapeutic opportunity in multiple sclerosis: evidence from monoclonal antibody therapy. J Neurol. 2006;253(1):98-108.

61. Paolillo A, Coles AJ, Molyneux PD, et al. Quantitative MRI in patients with secondary progressive MS treated with monoclonal antibody Campath 1H. Neurology. 1999;53(4):751-757.

62. Coles AJ, Fox E, Vladic A, et al. Alemtuzumab versus interferon beta-1a in early relapsing-remitting multiple sclerosis: post-hoc and subset analyses of clinical efficacy outcomes. Lancet Neurol. 2011;10(4):338-348.

63. Jones JL, Anderson JM, Phuah CL, et al. Improvement in disability after alemtuzumab treatment of multiple sclerosis is associated with neuroprotective autoimmunity. Brain. 2010;133(Pt 8):2232-2247.

64. Cox AL, Thompson SA, Jones JL, et al. Lymphocyte homeostasis following therapeutic lymphocyte depletion in multiple sclerosis. Eur $J$ Immunol. 2005;35(11):3332-3342.

65. Thompson SA, Jones JL, Cox AL, Compston DA, Coles AJ. B-cell reconstitution and BAFF after alemtuzumab (Campath-1H) treatment of multiple sclerosis. J Clin Immunol. 2010;30(1):99-105.

66. Duddy M, Niino M, Adatia F, et al. Distinct effector cytokine profiles of memory and naive human B cell subsets and implication in multiple sclerosis. J Immunol. 2007;178(10):6092-6099.

67. Somerfield J, Hill-Cawthorne GA, Lin A, et al. A novel strategy to reduce the immunogenicity of biological therapies. J Immunol. 2010;185(1):763-768.

68. Jones JL, Coles AJ. Campath-1H treatment of multiple sclerosis. Neurodegener Dis. 2008;5(1):27-31.

69. Jones JL, Coles AJ. Spotlight on alemtuzumab. Int MS J. 2009;16(3): 77-81.

70. Alcaide ML, Abbo L, Pano JR, et al. Herpes zoster infection after liver transplantation in patients receiving induction therapy with alemtuzumab. Clin Transplant. 2008;22(4):502-507.

71. Linker RA, Kieseier BC. Innovative monoclonal antibody therapies in multiple sclerosis. Ther Adv Neurol Disord. 2008;1(1):43-52. 
72. Jones JL, Phuah CL, Cox AL, et al. IL-21 drives secondary autoimmunity in patients with multiple sclerosis, following therapeutic lymphocyte depletion with alemtuzumab (Campath-1H). J Clin Invest. 2009;119(7):2052-2061.

73. Waggoner J, Martinu T, Palmer SM. Progressive multifocal leukoencephalopathy following heightened immunosuppression after lung transplant. J Heart Lung Transplant. 2009;28(4):395-398.

74. ClinicalTrials.gov. Comparison of Alemtuzumab and Rebif ${ }^{\circledR}$ Efficacy in Multiple Sclerosis, Study One (CARE-MS I). September 13, 2007. Available from: http://clinicaltrials.gov/ct2/show/NCT00530348?term= NCT00530348\&rank=1. Accessed September 14, 2011.
75. ClinicalTrials.gov. Comparison of Alemtuzumab and Rebif ${ }^{\circledR}$ Efficacy in Multiple Sclerosis, Study Two (CARE-MS II). October 22, 2007. Available from: http://clinicaltrials.gov/ct2/show/NCT00548405?term= care-ms+1\&rank=2. Accessed September 14, 2011.

76. Faderl S, Ferrajoli A, Wierda W, O’Brien S, Lerner S, Keating MJ. Alemtuzumab by continuous intravenous infusion followed by subcutaneous injection plus rituximab in the treatment of patients with chronic lymphocytic leukemia recurrence. Cancer. 2010;116(10):2360-2365.

77. Minagar A, Alexander JS, Sahraian MA, Zivadinov R. Alemtuzumab and multiple sclerosis: therapeutic application. Expert Opin Biol Ther. 2010;10(3):421-429.

\section{Publish your work in this journal}

Degenerative Neurological and Neuromuscular Disease is an international, peer-reviewed, open access journal focusing on research into degenerative neurological and neuromuscular disease, identification of therapeutic targets and the optimal use of preventative and integrated treatment interventions to achieve improved outcomes, enhanced survival and quality of life for the patient. The manuscript management system is completely online and includes a very quick and fair peer-review system. Visit http://www.dovepress.com/testimonials.php to read real quotes from published authors.

Submit your manuscript here: http://www.dovepress.com/degenerative-neurological-and-neuromuscular-disease-journal 